\title{
APRESENTAÇÃO
}

\section{Crime, polícia e sistema de justiça no Brasil contemporâneo: uma cartografia (incompleta) dos consensos e dissensos da produção recente das ciências sociais}

José Luiz Ratton ${ }^{1}$

São várias as possibilidades de identificação das origens da reflexão das ciências sociais brasileiras sobre os fenômenos do crime e da violência, do funcionamento das organizaçóes policiais, do Sistema de Justiça Criminal, das prisóes e das políticas públicas de segurança no país (ZALUAR, 1999; SANTOS; BARREIRA, 2016). De qualquer forma, não é difícil verificar a expansão, consolidação e diversificação de um campo institucional de pesquisas que abarcou tais fenômenos e que pode ser capturado analiticamente pelo que se convencionou chamar de sociologia da violência, embora conectado às outras ciências sociais (BARREIRA; ADORNO, 2010). O desenvolvimento de tal campo de conhecimento específico deve ser associado tanto à emergência do crime e da violência como problemas públicos no Brasil quanto ao debate sobre as diversas "soluçóes" possíveis, no plano das respostas estatais e societárias, para os problemas do controle social da violência e de produção e imposição da ordem social, em contextos históricos em que estão presentes tanto a democracia quanto o estado de direito (PAIXÃO, 1988).

Este número temático, Crime, polícia e sistema de justiça no Brasil contemporâneo, é tributário de um conjunto de balanços analíticos da produção nacional no âmbito da sociologia, da antropologia e da ciência política realizados ao longo dos últimos 25 anos. Passemos a eles.
$\mathrm{O}$ ponto de partida da interpretação da produção bibliográfica do campo é o pioneiro trabalho de Adorno (1993), publicado na revista $B I B \mathrm{n}^{\circ} 35$. Neste artigo, o autor buscou dar inteligibilidade à produção científica sobre a criminalidade urbana no Brasil desde os anos 1970. Observa e analisa o deslocamento da produção acadêmica centrada prioritariamente no conhecimento jurídico, com ênfase na legislação penal para um tipo de saber próprio das ciências sociais que apontava as articulaçóes eventuais entre tipo de desenvolvimento econômico, formas de exercício do poder e permanência de características do período autoritário nas instituiçóes de segurança pública e no Sistema de Justiça Criminal como fatores explicativos prováveis para o crescimento da violência, já percebida como problema social.

Alguns anos depois, o capítulo escrito por Zaluar (1999) para a coletânea organizada por Sergio Miceli sobre $O$ que ler na ciência social brasileira aponta criticamente algumas possibilidades de definição das violências na literatura das ciências sociais, problematiza as relaçóes entre violência, percepção desta e medo, acentua a necessidade de integração entre métodos quantitativos e qualitativos na pesquisa sobre o tema no país, debate os limites e possibilidades de explicaçôes dissuasórias e estruturais da criminalidade violenta, localiza as relaçóes entre violência institucional e ordem democrática e aponta

1 Professor do Programa de Pós-Graduação em Sociologia da Universidade Federal de Pernambuco (UFPE). E-mail: jl.ratton@gmail.com 
as conexóes entre a produção das ciências sociais e suas implicaçôes intencionais e não intencionais para as políticas públicas de redução da criminalidade.

$\mathrm{Na}$ mesma época, o ensaio publicado por Kant de Lima, Misse e Miranda (2000) na revista $B I B$ no 50 revela a regularidade, o crescimento, a diversificação e a legitimidade acadêmica da área de estudos voltada para a compreensão da violência, da criminalidade, da segurança pública e do Sistema de Justiça Criminal no Brasil. Ressalte-se aqui várias convergências analíticas entre este trabalho e aquele de Alba Zaluar, especialmente no mapeamento e na classificação dos problemas e temas centrais do campo de pesquisas que parece se consolidar no final dos anos 1990 e início dos anos 2000. Note-se, contudo, que as proposições de Kant de Lima, Misse e Miranda enfatizam os fatores de natureza estatal ligados à produção e reprodução da violência, ao passo que o balanço bibliográfico de Zaluar acentua, de forma própria, tanto os elementos de natureza política quanto os fatores de natureza cultural na reflexão sobre o mesmo fenômeno na produção acadêmica nacional.

É curioso perceber nos três balanços analíticos (ADORNO, 1993; ZALUAR, 1999; KANT DE LIMA; MISSE; MIRANDA, 2000) a presença sutil das formulaçóes de Antônio Luiz Paixão sobre as relaçóes entre democracia, ordem social, explicaçóes da criminalidade e interpretação do funcionamento das instituiçóes policiais e das políticas públicas de segurança (1988). O mineiro Paixão, desaparecido em meados dos anos 1990, produz uma interpretação poderosa da violência no Brasil que permanece atual. Através de uma síntese teórica original - que incorpora e funde densamente elementos da tradição sociológica interacionista e etnometodológica, contribuiçóes da sociologia das organizaçóes norte-americana contemporânea e os debates da ciência política dos anos 1970 e 1980 acerca da democracia e da cidadania - torna-se o elo analítico improvável entre a vigorosa produção sociológica da Universidade de Sáo Paulo sobre a violência e as formulaçóes sociológicas e antropológicas oriundas das universidades cariocas, nos anos que se seguem ao fim do regime militar e ao início da redemocratização do país.

No final da primeira década do século XXI, é publicada pela Anpocs a coleção Horizontes das ciências sociais no Brasil. No livro relativo à área de sociologia, o capítulo escrito por Barreira e Adorno (2010) atualiza, para a primeira década dos anos 2000, a análise do debate acerca da violência na sociedade brasileira no âmbito das ciências sociais. Além de dialogar diretamente com as revisóes bibliográficas anteriores aqui mencionadas, Barreira e Adorno apontam o surgimento de novas tendências de pesquisa: as relaçóes entre as novas configuraçôes urbanas, os mercados informais ilegais, os mercados de drogas e as organizaçóes criminosas; o surgimento de novas formas de delinquência urbana, as relações entre redes de negócios ilícitos, poder público e mercado, a expansão e diversificação dos estudos sobre homicídios, a permanência de distintas formas organizacionais no âmbito da criminalidade de rua (quadrilhas, gangues, grupos de extermínio); as formas emergentes de intervenção estatal e seu impacto nas políticas de segurança, as possibilidades e limites das reformas das instituiçóes policiais, a participação da sociedade civil nas políticas públicas de segurança, as novas formas de administração institucional dos conflitos, os novos padrões de punição, o encarceramento em massa e suas consequências.

Recentemente, Santos e Barreira (2016) propuseram uma interpretação alternativa do campo de estudos sobre conflitos, crime e violência no Brasil, em texto introdutório ao livro que trata de temática semelhante voltada para o conjunto de países da América 
Latina. Os autores buscaram rastrear o tema da violência nas ciências sociais brasileiras a partir da interpretação de suas manifestaçóes no mundo agrário e rural, articulando as permanências e rupturas em diferentes tempos históricos, suas diversas formas de manifestação no presente, tanto em contextos de "sertão" quanto em cenários urbanos. A proposição geral postulada é que os fenômenos da violência e do crime e das diferentes formas de ação/reação estatal a estes sejam tratados por meio do conceito de conflitualidade, que teria abrangentes pretensóes de multidimensionalidade.

Finalmente, há a interpretação proposta por Campos e Alvarez (2017), realizada a partir de uma extensa revisão de todos os artigos relacionados à sociologia da violência em revistas classificadas como A1 pelo comitê da área de sociologia da Capes entre 2000 e 2016. A identificação de três subcampos supostamente concorrentes num maior âmbito - políticas públicas, violências e sociabilidades, sociologia da punição - é seguida por uma análise dos problemas teórico-metodológicos concernentes a cada um deles. O subcampo da segurança pública carregaria uma dimensão estatizante, concebida como indesejável, tanto por ceder às pressóes de uma agenda estatizante quanto pela subteorização e baixa articulação, com uma perspectiva do crime e da violência em um plano societário. O subcampo das violências e sociabilidades, voltado para a compreensão das sociabilidades alternativas e a organização social do crime, estaria livre da influência estatal, o que resguardaria seu perfil crítico, apesar do abandono - relativo - da teoria social. Já a chamada sociologia da punição, o terceiro subcampo, carregaria qualidades desejáveis para a pesquisa sociológica: compromisso teórico e distância crítica do estado. Teria como desafio a superação de uma visão da punição como fenômeno relativamente autônomo de determinaçôes estruturais nos planos econômico e político. ${ }^{2}$

É na esteira destas diversas interpretações do estado da arte da produçáo sobre o tema $\mathrm{da}$ violência que deve ser enquadrado este número temático. Composto por seis artigos, buscou expandir e desenvolver alguns tópicos de pesquisa, problemas teóricos e questôes metodológicas mapeados nas publicaçôes anteriores para outros períodos.

Desta forma, a seleção de temas aqui proposta pretendeu tanto atualizar o já abordado quanto propor uma investigaçáo mais densa sobre áreas menos exploradas nas revisões bibliográficas anteriores. Obviamente não se trata de cobertura exaustiva de uma área em franco crescimento quantitativo e relevante diversificação qualitativa interna. Os artigos compóem um mosaico de tensa pluralidade teórica e metodológica, traço constituinte e estruturador desta área de estudos e pesquisas, tanto no plano dos compromissos

2 Dois livros relativamente recentes compóem o cenário antecedente e relacionado a este número especial: o primeiro, organizado por Lima e Ratton (2011), com entrevistas biográficas (e obituários) dos pioneiros do campo de estudos sobre crime, violência e direitos humanos no país (Alba Zaluar, Antônio Luiz Paixão - in memoriam, César Barreira, Claudio Beato, Edmundo Campos Coelho - in memoriam, Gláucio Soares, José Vicente Tavares Santos, Julita Lemgruber, Luciano de Oliveira, Luiz Eduardo Soares, Maria Stela Grossi Porto, Michel Misse, Paulo Sérgio Pinheiro, Roberto Kant de Lima e Sérgio Adorno), e o segundo, organizado por Lima, Ratton e Azevedo (2014), que contou com a contribuição de mais de oitenta pesquisadores ligados a vários grupos de pesquisa e programas de pós-graduação em ciências sociais (e outras áreas) espalhados pelo país, em sua grande maioria ligados às universidades públicas brasileiras. Tal publicação revelaria a um só tempo a abrangência, as fronteiras epistemológicas e o desenvolvimento do campo, e concomitantemente a diferenciaçáo temática interna e a pluralidade teórica e metodológica que orienta as pesquisas sobre crime, violência e sistema de justiça criminal no Brasil. 
normativos quanto das escolhas teóricas e opçôes metodológicas. ${ }^{3}$

Embora os ensaios desta publicação conversem entre si, identifica-se dois blocos temáticos principais. No primeiro, questôes de natureza metodológica constituem o ponto de partida para a problematização das perspectivas de análise dos fenômenos do crime e da violência, explorando uma linha analítica que, apesar de anunciada nas revisóes anteriores, ainda náo havia sido objeto de uma reflexão mais focalizada. No segundo bloco, o debate se volta para a interpretação da produção científica sobre algumas das instituiçôes de controle social - polícias, sistema de justiça criminal e prisóes.

$\mathrm{O}$ artigo que abre este número especial, "O calcanhar de Aquiles dos estudos sobre crime, violência e dinâmica criminal”, de Ludmila Ribeiro e Alex Niche Teixeira, revisa as estratégias metodológicas utilizadas por cientistas sociais nos estudos sobre crime e violência no Brasil, a partir de uma base de 546 artigos publicados em periódicos classificados como A1 ou A2 pelo comitê da área de sociologia. Constata, de forma peculiar e amparada em dados, o perfil predominantemente "qualitativista" da pesquisa em ciências sociais voltada à violência. À prevalência da entrevista como técnica preferencial de coleta de dados se associa a ascensão da etnografia como recurso metodológico na compreensão do crime. $\mathrm{O}$ ponto frágil dos estudos de tal fenômeno no plano metodológico das ciências sociais tem sido, segundo a intepretação proposta por Ribeiro e Teixeira, a incapacidade de utilização de metodologias quantitativas robustas de coleta de informaçôes e de análise de dados, limitando a realização de estudos comparativos e de possibilidades de generalização, ainda que controladas.

O texto de Arthur Trindade M. Costa e Renato Sérgio de Lima, "Estatísticas oficiais, violência e crime no Brasil", defende que a principal limitação metodológica no tocante aos estudos sobre criminalidade e violência no Brasil está relacionada à inexistência de estatísticas criminais e policiais padronizadas em nível nacional. A incapacidade de produção de séries históricas de informaçôes criminais, incorporando outros tipos criminais que não homicídios, a quase inexistência de pesquisas de vitimização, as informaçóes precárias relativas ao fluxo criminal no âmbito do sistema de justiça, constituiriam fatores restritivos ou impeditivos para o desenvolvimento de análises quantitativas mais sofisticadas dos fenômenos criminais e das respostas públicas ao crime. Tais fatores limitariam a construção de análises comparadas entre estados ou municípios de diferentes estados (convergindo com a análise proposta por Ribeiro e Teixeira), e constituiriam sérios obstáculos à avaliação de políticas públicas de segurança em todos os níveis.

Em linha de análise divergente, o artigo de Jania P. D. Aquino e Daniel Hirata, "Inserçóes etnográficas ao universo do crime: algumas consideraçôes sobre pesquisas realizadas no Brasil entre 2000 e 2017", defende o valor analítico das etnografias e da teoria etnográfica como estratégias teórico-metodológicas positivadoras do crime como prática social. Os autores, por meio do mapeamento dos principais trabalhos sobre dinâmicas do crime e da violência produzidos no país, revelam a importância do uso das etnografias como recurso teórico-metodológico, acentuando o ganho compreensivo das dinâmicas criminais

3 Vale ressaltar que as autoras e os autores dos textos deste número temático, assim como este organizador, são pesquisadores de grupos de pesquisa consolidados sobre o tema, em sua maior parte vinculados a programas de pós-graduação em sociologia de universidades de quatro diferentes regiōes do país (três do Nordeste, dois do Centro-Oeste, sete do Sudeste e dois do Sul). 
e dos personagens envolvidos no universo do crime. A possibilidade de refinamento de conceitos e vieses analíticos provocada por tais etnografias estaria assentada na premissa de "levar a sério" a perspectiva nativa e escapar das terminologias jurídicas ou das normatividades externas aos contextos de ação. Um ponto relevante diz respeito às possibilidades de articular, no plano etnográfico, dimensóes políticas, econômicas, institucionais e morais no âmbito das economias ilegais e dos coletivos criminais. Outra questão da maior importância no trabalho de Aquino e Hirata é a discussão dos limites éticos da pesquisa socioantropológica sobre ilegalidades e ilegalismos e das eventuais reaçóes estatais às pesquisas de campo realizadas por cientistas sociais nesta área.

O segundo bloco de contribuiçóes tematiza a produção sobre violência e crime através do mapeamento recente dos estudos sobre polícias, sistema de justiça criminal e prisóes no Brasil contemporâneo.

O ensaio que abre este bloco, de autoria de Jacqueline Muniz, Haydée Caruso e Felipe Freitas, tem por título "Os estudos policiais nas ciências sociais: um balanço sobre a produção brasileira a partir dos anos 2000”. Esta análise aponta criticamente para dois traços da literatura estudada: o primeiro, relativo a um compromisso quase apriorístico com um conceito estático de cultura policial, que orienta a interpretação para a atribuição de disposiçóes organizacionais voltada quase necessariamente para a guerra ou o confronto, empobrecendo as sutilezas analíticas, as variações dentro das organizaçôes, limitando as possibilidades de mudança factíveis. O segundo traço seria a preferência por uma ciência social dos problemas policiais (ou uma ciência social aplicada à polícia) em contraposiçáo a uma socioantropologia compreensiva das polícias. Para os autores, a demanda pública por reformas no presente termina por dirigir a atenção analítica para o que é ou pode ser considerado problemático ou indesejável nas organizaçôes policiais brasileiras, buscando assim mais do que mapear, compreender e explicar as dinâmicas policiais, sejam elas problemáticas ou náo.

Logo a seguir, o artigo de Rodrigo Ghiringhelli de Azevedo e Jacqueline Sinhoretto, "O sistema de justiça criminal na perspectiva da antropologia e da sociologia”, constata que a literatura recente sobre o funcionamento da justiça brasileira identifica, em novos termos, a permanência da tradiçáo inquisitorial, a adesão minoritária ao campo dos direitos humanos e a predominância de concepçôes morais que fortalecem desigualdades de gênero e de classe no âmbito das organizaçōes do Sistema de Justiça Criminal. As variaçóes legislativas em matéria criminal e penal (política de drogas, administração institucional da violência contra a mulher, ampliação de alternativas penais à prisão etc.) sáo analisadas tanto do ponto de vista das inovaçóes que aparentemente sugerem quanto das contradiçôes e paradoxos resultantes das moralidades organizacionais em conflito e de seus resultados práticos. Os autores concluem, a partir da análise da bibliografia, que os esforços reformadores e inovadores não foram por si só capazes de gerar alteraçôes substantivas em direção democratizante. $\mathrm{O}$ ativismo judicial, especialmente do Ministério Público, não teria sido acompanhado por mudanças nos compromissos valorativos e nas práticas organizacionais legitimadoras de concepçóes conservadoras da ordem e de manutenção das hierarquias sociais.

Finalizando este número, há o artigo "Estudos sobre prisão: um balanço do estado da arte nas ciências sociais nos últimos vinte anos no Brasil" de autoria de Luiz Claudio Lourenço e Marcos César Alvarez. Os autores identificam um crescente interesse nesta subárea de pesquisa, particularmente 
nas investigaçóes sobre as relaçóes de poder dentro das prisóes, as "gangues prisionais", suas relaçóes com a administração pública, seus impactos internos e externos às prisóes. Sobressai também, de acordo com os autores, a expansão dos estudos sobre mulheres encarceradas, sobre o papel da religião nas penitenciárias e sobre os agentes prisionais. Apontam o incremento das pesquisas sobre a relação eventual de políticas prisionais com discursos punitivos, assim como sobre as próprias políticas. A baixa densidade de estudos comparados com outros países é percebida pelos autores como um indicador de baixo cosmopolitismo das pesquisas sobre as prisóes no Brasil.

Como foi dito acima, a discussão realizada neste número temático buscou atualizar, expandir e desenvolver alguns tópicos presentes nas análises bibliográficas de outros períodos históricos no interior do campo de estudos sobre violência, crime, polícia, Sistema de Justiça Criminal e prisóes no país.

Decerto ainda restam territórios temáticos e disciplinares a serem desbravados. A produção científica da ciência política na área, ainda que sem a pujança da sociologia e da antropologia, carece de mapeamento específico, com critérios teórico-metodológicos específicos. A criminologia radical brasileira, com presença expressiva nas faculdades de direito, talvez mereça uma análise pormenorizada exclusiva.

Os artigos que compóem esta publicação também permitiram a visualização de objetos de pesquisa pouco abordados na literatura. No âmbito do funcionamento do Sistema de Justiça Criminal, o estudo das defensorias ainda tem pouca visibilidade; no plano das organizaçóes policiais, pesquisas sobre as polícias científica e federal ainda são escassas; o debate sobre as inúmeras e complexas questões éticas relativas a crime e violência ainda é um tópico das ciências sociais pouco explorado. As possibilidades e limites de articulação teórica e metodológica do tema em outras áreas do conhecimento, como a economia, a geografia e a saúde pública, é uma questão a ser enfrentada. A utilização de modelos explicativos do crime e da violência ancorados nas pesquisas realizadas no Rio de Janeiro e em São Paulo, ainda que menos acentuada do que em passado recente, constitui por vezes um obstáculo ao entendimento das singularidades da distribuição social da violência nos diferentes territórios sociais do país e podem encobrir diferenças substantivas de organização social do crime, que poderiam ser objeto de rica análise comparada.

O campo é vasto e diverso, e as formas de pensá-lo, também. No âmbito dos desacordos, mesmo que tácitos, uma pergunta estruturante se impôe: como nomear um campo tão amplo e com tantas possibilidades políticas, teóricas, metodológicas? Criminologia, sociologia da violência, sociologia do crime, sociologia das conflitualidades, segurança pública, segurança cidadã, sociologia da punição? O debate é longo e não cabe nesse espaço, mas de toda maneira é possível dizer que as filiaçôes normativas e institucionais que possivelmente orientam as diversas escolhas teóricas e metodológicas de algum modo delimitam as múltiplas possibilidades de convergência e divergência em todos os níveis citados.

O balanço provisório proposto neste número temático aponta para algum acúmulo de conhecimento na área, tanto substantivo, na modesta opinião deste organizador, quanto na construção relativamente civilizada dos pontos de divergência e desacordos teóricos e metodológicos. As tensóes entre os limites e possibilidades de utilização da etnografia ou de análises estatísticas do crime e da violência não são características exclusivas deste campo de estudos. As controvérsias oriundas do uso de tal ou qual orientação teórica na interpretação do universo do crime também não 
constitui novidade. A avaliação do potencial crítico de perspectivas de investigação das dinâmicas criminais centradas em maior ou menor grau no Estado e nas políticas públicas de segurança constitui, para o organizador deste número temático, um objeto de debate ainda a ser explorado, mas que pode ser convertido em ponto de articulação e interesse das diferentes concepçóes teóricas e metodológicas disponíveis no campo.

Se a sociologia, a antropologia e a ciência política são, de forma geral, campos científicos multiparadigmáticos em que a legitimidade do objeto e da análise é dependente de validação no plano explicativo e no plano discursivo
(ALEXANDER, 1987), não seria possível esperar algo diferente de um campo de produção do conhecimento interdisciplinar como o dos estudos sobre crime, violência, polícia e sistema de justiça criminal. Paradoxalmente, o desacordo (relativo) como regra de convivência náo tem se constituído como impedimento para o avanço do conhecimento sobre o crime e a violência no país.

Este número especial não seria possível sem a presença competente de Márcia Consolim, editora chefe da Revista de Informação Bibliográfica em ciências sociais, e o apoio eficiente de Mirian Silveira. Agradeço também a contribuição dos pareceristas anônimos.

\section{Referências}

ADORNO, S. A criminalidade urbana violenta no Brasil: um recorte temático. Revista Brasileira de Informação Bibliográfica em Ciências Sociais, Rio de Janeiro, n. 35, p. 3-24, jan./jun. 1993.

ALEXANDER, J. C. O novo movimento teórico. Revista Brasileira de ciências sociais, Rio de Janeiro, v. 2, n. 4, p. 5-28, 1987.

BARREIRA, C.; ADORNO, S. A violência na sociedade brasileira. In: MARTINS, C. B.; MARTINS, H. H. T. S. (Orgs.). Horizontes das ciências sociais no Brasil: sociologia. São Paulo: Anpocs, 2010. p. 303-374.

CAMPOS, M. S.; ALVAREZ, M. C. Políticas públicas de segurança, violência e punição no Brasil (2000-2016). In: MICELI, S.; MARTINS, C. B. (Orgs.). Sociologia brasileira hoje. São Paulo: Ateliê, 2017. p. 143-217.

KANT DE LIMA, R.; MISSE, M.; MIRANDA, A. P. M. Violência, criminalidade, segurança pública e justiça criminal no Brasil: uma bibliografia. Revista Brasileira de Informaçäo Bibliográfica em Ciências Sociais, Rio de Janeiro, n. 50 , p. 45-124, 2000.

LIMA, R. S.; RATTON, J. L. As ciências sociais e os pioneiros nos estudos sobre crime, violência e direitos humanos no Brasil. São Paulo: Fórum Brasileiro de Segurança Pública; Urbania; Anpocs, 2011.

LIMA, R. S.; RATTON, J. L.; AZEVEDO, R. G. (Orgs.). Crime, polícia e justiça no Brasil. São Paulo: Contexto, 2014.

MESQUITA NETO, P. Ensaios de segurança cidadã. São Paulo: Quartier Latin, 2011.

PAIXÃO, A. L. Crime, controle social e consolidação da democracia: as metáforas da cidadania. In: REIS, F. W.; O’DONNEL, G. (Orgs.). A democracia no Brasil: dilemas e perspectivas. São Paulo: Vértice, 1988. p. 168-199. 
SALLA, F. A pesquisa sobre prisôes: um balanço preliminar. In: KOERNER, A. (Org.). História da justiça penal no Brasil: pesquisas e análises. São Paulo: IBCrim, 2006. p. 107-128.

SANTOS, J. V. T.; BARREIRA, C. Introdução: a construção de um campo intelectual: violência e segurança cidadã na América Latina. In: (Orgs.). Paradoxos da segurança cidadã. Porto Alegre: Tomo, 2016. p. 9-40.

ZALUAR, A. Violência e crime. In: MICELI, S. (Org.). O que ler na ciência social brasileira: 1970-1995. São Paulo: Anpocs, 1999. p. 13-107. 